\title{
$\mathbf{R}$

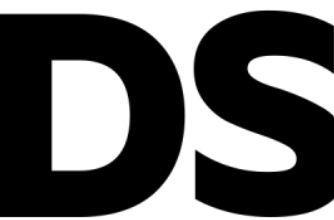

\section{RAÇA E EDUCAÇÃO: DE MANOEL BOMFIM À PAULO FREIRE, UMA LEITURA DECOLONIAL}

Recebido em: $13 / 10 / 2021$

Aprovado em: 20/12/2021

Resumo: A questão racial tem sido debatida por epistemologias marginais a exemplo do pensamento descolonial que tem como conceito principal a Colonialidade do Poder. Este artigo, em perspectiva marginal, busca refletir sobre a articulação entre colonialismo, educação e raça no Brasil. Objetiva demonstrar que uma educação libertadora tal como apregoada por Paulo Freire (1987) passa pelo empreendimento de criticar o colonialismo e a colonialidade. Para tanto, traz como subsídio teórico os intelectuais brasileiros Manoel Bomfim e Paulo Freire (1987), especificamente o conceito de parasitismo social cunhado pelo primeiro e a proposta de educação libertária do segundo a partir da superação do dilema oprimido-opressor.

Palavras-chave: Parasitismo Racial. Modernidade. Colonialidade do Poder. Educação. Oprimidoopressor.

\section{RACE AND EDUCATION: FROM MANOEL BOMFIM TO PAULO FREIRE, A DECOLONIAL READING}

Abstract: The racial issue has been debated by marginal epistemologies such as decolonial thinking, whose main concept is the Coloniality of Power. This article, from a marginal perspective, seeks to reflect on the articulation between colonialism, education, and race in Brazil. It aims to demonstrate that a liberating education as advocated by Paulo Freire (1987) goes through the undertaking of criticizing colonialism and coloniality. To do so, it brings as theoretical support the Brazilian intellectuals Manoel Bomfim and Paulo Freire (1987), specifically the concept of social parasitism coined by the former and the latter's proposal of liberating education based on overcoming the oppressor-oppressed dilemma.

Keywords: Racial Parasitism. Modernity. Coloniality of Power. Education. Oppressed-oppressor.

\section{RAZA Y EDUCACIÓN: DE MANOEL BOMFIM A PAULO FREIRE, UMA LECTURA DECOLONIAL}

Resumen: La cuestión racial ha sido debatida por epistemologías marginales como el pensamiento decolonial, cuyo concepto principal es la Colonialidad del Poder. Este artículo, en una perspectiva marginal, busca reflexionar sobre la articulación entre colonialismo, educación y raza en Brasil. Pretende demostrar que una educación liberadora como la que propugna Paulo Freire (pasa por la empresa de criticar el colonialismo y la colonialidad. A tal fin, trae como base teórica a los intelectuales brasileños Manoel Bomfim y Paulo Freire, concretamente el concepto

\footnotetext{
${ }^{1}$ Doutora em Ciências da Religião. Professora do curso de Ciências da Religião da Universidade Estadual de Montes Claros (UNIMONTES). Professora visitante do Programa de Pós-Graduação em Ciências da Religião da Pontifícia Universidade Católica de Minas Gerais (PUC-MINAS). E-mail: cristinaborgesgirasol@gmail.com. ORCID: http://orcid.org/0000-0002-4193-5377.
} 
de parasitismo social acuñado por el primero y la propuesta de educación liberadora del segundo basada en la superación del dilema oprimido-opresor.

Palabras-clave: Parasitismo racial. Modernidad. Colonialidad del poder. Educación. Oprimidoopresor.

\section{INTRODUÇÃO}

As reflexões que seguem integram o rol das meditações que se erguem no momento atual. Este, oportuno para trazer à tona pensamentos que pareciam seguir o curso das voltas na árvore do esquecimento².

O tempo pandêmico, que denominamos como coronacrisis, claramente denuncia o espaço-momento da diferença colonial (MIGNOLO, 2003) onde o sentimento de finitude coletivo, arde em meio ao devir das contradições, ambivalências, reafirmações, antagonismos, rupturas e continuísmos da sociedade brasileira. Experiências de finitude apimentam a diferença colonial ao trazer à tona, em desvelamentos nada tímidos, "velhos" ideais raciais. Se o coronacrísis possibilitou a muitos assumir publicamente suas ideias fundamentalistas, parece também que provocou o desaceleramento da marcha em torno da árvore do esquecimento.

A academia brasileira em streaming populariza Lives com temáticas voltadas para as reivindicações de grupos minoritários a exemplo do movimento negro. A questão racial ganha notoriedade. O cotidiano de violências da população negra passa a provocar espantos e preocupações diante do alto índice de assassinatos a pessoas negras no Brasil. Mas, o coronacrisis também escancara em imagens e depoimentos o que a sociedade brasileira sempre soube mas pouco tem se mobilizado em busca de soluções práticas: a fragilidade da educação brasileira e do sistema público que a gesta.

No propósito de articular educação e raça em perspectiva descolonizadora, o presente artigo tece reflexões sobre a necessidade de se estabelecer no Brasil uma educação popular de(s)colonial como forma de superação do parasitismo social e da colonialidade do poder presentes na tensão oprimido-opressor denunciada por Paulo Freire (1987).

\footnotetext{
${ }^{2}$ No intuito de liquidar os elos com a África e sua cultura ancestral, africanas e africanos eram obrigados, antes de embarcar nos navios negreiros como escravas e escravos, ao ritual de passar de sete (mulheres) a nove (homens) voltas em torno de uma árvore, na costa do Benin, que passa a ser conhecida como árvore do esquecimento.
} 
Em perspectiva de(s)colonial, aposta na educação enquanto ferramenta política de transformação no espaço da diferença colonial à luz de críticos periféricos como os brasileiros Manoel Bomfim (1868-1932) e Paulo Freire (1921-1997). Se coloca enquanto oportunidade para volver à história brasileira onde a colonialidade do poder forjou exterioridades parasitárias comprometendo o desenvolvimento de consciências críticas ao estimular as voltas na árvore do esquecimento.

$\mathrm{O}$ artigo se estrutura da seguinte forma: em um primeiro momento apresenta a crítica ao colonialismo latino-americano empreendida pelo brasileiro Manoel Bomfim (2008) alargando seu conceito de parasitismo social para parasitismo racial. Isso, no propósito de demonstrar a importância desse autor que, no início do século XX e na contramão dos debates políticos e acadêmicos sobre a miscigenação dos povos latinoamericanos como fator de atraso moral, econômico e intelectual, chamava a atenção para a necessidade de uma educação popular como forma de libertação dos males que comprometiam o espírito latino-americano.

Um desses males, a inferioridade imposta aos povos latino-americanos pelas teorias raciais europeias. Inferioridade que ainda nos prende à subjugação e à dominação coloniais e somente superadas mediante uma ampla educação popular; 0 segundo momento traz uma breve discussão conceitual sobre colonialidade do poder, modernidade e desprendimento no propósito de situar na perspectiva da de(s)colonialidade o parasitismo racial. Esta, parte sugere o parasitismo racial como o que hoje se denomina de racismo estrutural; Em seguida, o artigo finaliza trazendo o excepcional Paulo Freire e o iluminador dilema oprimido-opressor apontado por ele como o obstáculo para o desmantelamento das redes que integram a alienação. Neste texto, tal dilema é vislumbrado à luz da questão racial.

\section{A CRÍTICA AO COLONIALISMO EM MANOEL BOMFIM: PARASITISMO RACIAL E DEGENERAÇÃO}

No início do século XX, o crítico do colonialismo, o intelectual brasileiro Manoel Bomfim apostava na educação como instrumento para a extinção dos males causados pela permanência desse sistema de exploração e dominação na América Latina. A produção acadêmica deste pensador em torno da educação, da identidade e da formação da nacionalidade brasileira tinha como eixo o conceito de parasitismo social: 
enfermidade sociocultural e política que assolava principalmente as elites brasileiras ${ }^{3}$.

O parasitismo social, segundo Bomfim (2008, p.67), foi o modelo de colonização europeia que se traduzia em um viver, pelo dominador, "às custas de iniquidades e extorsões". Uma enfermidade presente no fluxo das relações sociais que comprometia o desenvolvimento do Brasil e da América Latina por várias gerações.

Bomfim reflexionava à frente do seu tempo, um pensador dissidente no contexto do entusiasmo provocado pela ascensão republicana no Brasil. Enquanto a intelectualidade brasileira recorria às teorias raciológicas para explicarem o que entendiam como atraso da nossa nação - frente à evolução ${ }^{4}$ das nações europeias -, imbuído de uma cultura humanística Manoel Bomfim questionava a natureza classista do novo governo instaurado após a Proclamação da República brasileira. Governo este distante dos ideais políticos presentes no pensamento republicano. Bomfim rechaçava as teorias que afirmavam a mistura de raças e a presença africana no Brasil como potencializadores do nosso atraso.

$\mathrm{Na}$ esteira deste pensador é possível dizer que as nações europeias, quando chegam em Abya Yala ${ }^{5}$, já estavam viciadas no parasitismo, isto é, estavam viciadas em "viver às custas de iniquidades e extorsões". Instituem o Estado como forma de garantir tributos e extorsões, distribuem terras para as classes dominantes, escravizam o índio, depois o negro africano e, em seguida os mestiços. Exploram os recursos naturais de Abya Yala e direcionam sua riqueza para a Europa de forma tal que todo o mundo direta ou indiretamente passa a de sua seiva.

Estabelece-se, a partir do sangue vital de Abya Yala, a América e a partir dela, a nível mundial, o parasitismo racial. Uma das características desse parasitismo é a urbanização enquanto ideal de vida moderna o que na Europa, após o século XVI, estimula o abandono dos campos e, consequentemente, a diminuição da produção agrícola. Para evitar a escassez de alimentos nesse continente, o modelo parasitário moderno se instala fortemente nas colônias a ponto de vidas indígenas, africanas e de seus descendentes serem sacrificadas.

\footnotetext{
${ }^{3} \mathrm{O}$ destaque dado por Bomfim às elites se deve ao fato de, no início do século $\mathrm{XX}$, apenas os privilegiados tinham acesso à educação.

${ }^{4}$ Desenvolvimento técnico e racionalidade.

${ }^{5}$ Nome do continente americano antes da dominação europeia. Na língua do povo Kuna, significa terra madura, terra viva. O termo carrega a noção de ser vivo independente dos seres humanos.
} 
A naturalização da exploração e da violência nas colônias impede suas elites, a exemplo da brasileira, bem como a massa colonial e colonizadora de compreender a vida de outra forma, isto é, ausente de hierarquias. Nos dizia Bomfim em sua obra América Latina. Males de origem (2008):

Só o escravo trabalhava, só ele era produtivo. E com isto resultou que o trabalho foi considerado, cada vez mais como coisa vil, infamante. $\mathrm{O}$ ideal para todos era viver sem nada fazer - ter escravos e à custa deles passar a vida e enriquecer. (BOMFIM, p.36)

A partir dessa cita não nos é difícil perceber o cunho racial do parasitismo predador que se desenvolvia nas sociedades latino-americanas. Segundo Bomfim, a lógica parasitária de exploração contava com o apoio de instituições tais como o Estado e a Religião. O estado por ser destituído de sua utilidade pública mantendo a corte, as elites, os empregados do fisco e aplicando uma justiça que apenas condenava. A Igreja, amparada pelo Estado, estendia "a sua trama sobre a nova sociedade que se vai formando; escraviza os espíritos, assegura a obediência das populações, semeia superstições, de modo a tornar quase impossível qualquer tentativa de reforma e progresso social". (BOMFIM, 2008)

Percebe-se na reflexão que empreende sobre os males da América Latina empreendida o tom libertário e descolonizador. No limbo do pensamento social e do debate educacional nos primeiros anos do século XX no Brasil, Manoel Bomfim era um dissidente frente às teorias evolucionistas e deterministas de cunho racial que dominavam a academia brasileira preocupada com o nacionalismo. Os debates acerca desse, pode-se dizer, oficializava o racismo que hoje denominamos de estrutural.

No entanto, este crítico do colonialismo latino-americano desconstrói a teoria da superioridade racial presente entre os intelectuais nativos influenciados pela auto narrativa europeia de superioridade. Nos diz ele sobre essa teoria:

De acordo com esses princípios, os indígenas americanos, os pretos africanos, os negróides e malaios da Oceania, foram declarados "inferiores", em massa. Para estes o julgamento é definitivo; a sociologia oficial da Europa e dos Estados Unidos decretou que eles são "inferiores", pois que se acham todos em estado social inferior ao dos outros povos: "As grandes nações devem ir colonizar-Ihes as terras". (...). A teoria não deixaria de ser falsa e 
imoral, mas não seria inconseqüente, se eles não competissem também entre si, e se, lá mesmo na Europa, não pretendessem dominar uns aos outros. É aqui que aparecem principalmente as extravagâncias e absurdos da teoria. Diz ela que os superiores devem governar os inferiores - porque estes são incapazes, absolutamente incapazes, de atingir uma civilização adiantada; ao mesmo tempo, proclama que os anglo-saxões são os "superiores" porque dominam hoje dois terços da Terra. Destarte, a superioridade da raça, (...), deixa de ser definitiva. Estes, que são superiores hoje, eram inferiores há dois séculos. (BOMFIM, 2008, 193)

Quatro décadas antes de Frantz Fanon e Aimé Césaire, Manoel Bomfim chamava a atenção para o fato de teorias deterministas de cunho racial, presentes no debate sobre o nacionalismo brasileiro na passagem do século XIX para o século XX, serem convenientes para justificar a dominação. Teorias raciológicas estão de acordo com a lógica do imperialismo presente "no eterno conflito dos oprimidos e espoliados com a exploração dominante - dos parasitados e parasitas". (BOMFIM, 2008, p. 231)

Este pensador brasileiro, no início do século $X X$, já sinalizava para o fato da hierarquia racial ser o sustentáculo das relações de poder amparadas no capitalismo. Ele nos alerta: "Quando nos consideram como países atrasadíssimos, têm certamente razão, não é tal juízo que nos deve doer, e sim a interpretação que dão a esse atraso, e principalmente as conclusões que daí tiram, e com que nos ferem" (BOMFIM, 2008, p. 49).

Em perspectiva marginal de(s)colonial não causa surpresa a razão encontrada pelas potências europeias para o que entendiam como atraso político, social e moral dos países latino-americanos: a questão a racial. O fato de sermos um povo que se distingue pela mestiçagem e, no caso brasileiro, marcado fortemente pelas raças que foram parasitadas, o indígena e o africano. A auto narrativa europeia constrói o que as epistemologias do sul denominam de Modernidade europeia, isto é, o relato europeu sobre sua superioridade cultural, técnica, racial, epistémica e religiosa.

No entanto, de acordo com o nosso pensador, o parasitismo leva à degeneração: "Sempre que há uma classe ou uma agremiação parasitando sobre o trabalho de outra, aquela -o parasita - se enfraquece, decai, degenera, extingue-se. É fato reconhecido e geralmente mal interpretado, mas em todo caso incontestável." (BOMFIM, p. 56).

A degeneração não pode ser interpretada a partir de binômios simples como se 
entre lugares, interstícios subjetivos e físicos, formados na relação tensional entre o parasita e o parasitado não fossem criados no contato entre os mesmos. A degeneração se faz ver no "novo" que surge a partir dessa relação, isto é, na cultura, na estética, na religião e nos comportamentos. As gerações posteriores, oriundas dessa relação, herdam a degenerescência e reproduzem o parasitismo. A degenerescência é um processo que deve ser interrompido para o desaparecimento absoluto do parasitismo.

O pensamento bomfimiano nos leva a pensar na necessidade de operacionalizar a realidade moderna a partir de outra lógica que não seja a colonial tal como nos reiteram os militantes da de(s)colonialidade Aníbal Quijano e Walter Mignolo. O que requer desprendimento.

Operar em outra lógica tem urgência nos sugere o intelectual brasileiro que, libertador e descolonizador e, com nuances interculturais, na contramão da intelectualidade do nosso país à época, conclamava-nos a um esforço nacional para superação do atraso social, econômico, político e moral: a difusão da instrução básica que para ele deveria ser popular e plena.

O passado colonial da América Latina não era razão para a prostração e apatia que inundava as elites brasileiras. A libertação das amarras imperialistas é possível e, o povo deve ser motivado a refletir sobre "[...] a necessidade imprescritível de atender-se à instrução popular, se a América Latina se quer salvar. [...] Aí está o remédio contra nosso atraso, contra a miséria geral" (BOMFIM, 2008, p. 329). De acordo com esse pensador, os governos na América Latina devem:

[...] em nome de um regime democrático e livre [...], fazer desaparecer dentre os indivíduos essa causa de desigualdade, essa causa de inferioridade intelectual e econômica e de incapacidade política - qual o 'não saber ler nem escrever'?" (BOMFIM, 2008, p.337).

\section{MODERNIDADE, COLONIALIDADE DO PODER E DESPRENDIMENTO}

É compreensível porque, para Bomfim, um ensino massivo das classes populares proporcionaria a cura do parasitismo social. Subjetividades autônomas, via intersubjetividade, são capazes de disseminar desprendimentos e frear a naturalização de ideais parasitários. $E$, se consideramos o parasitismo racial enquanto enfermidade alastrada pelo colonialismo compreendemos melhor a conhecida sentença: a educação 
é o antídoto para o racismo (Silvio Almeida). Antes mesmo que se falasse em racismo estrutural, Manoel Bomfim o sugeria com o conceito de parasitismo social.

O sentido dado à educação por nosso crítico do colonialismo, portanto, é o de libertação do parasitismo sócio racial que proporciona o atraso moral e a miséria social. Uma proposta de educação liberadora com forte sentido político, e de(s)colonial foi apresentada décadas depois pelo excepcional Paulo Freire.

Freire (1987) concebia a educação como não restrita ao ensino formal como apregoado por Bomfim. A educação deveria incluir os contextos social, políticos, epistémicos e existenciais com vistas à participação popular na criação de propostas, ações educacionais e políticas de libertação.

Ensinar para Freire é um ato político o que torna sua aposta educativa de(s)colonial. Algo que a militante da de(s)colonialidade Catherine Walsh (2014) compreendeu a ponto de em Paulo Freire se balizar para criar a Pedagogia Decolonial. Uma pedagogia apropriada para as sociedades forjadas no bojo da opressão colonial e imperial. Uma pedagogia libertadora.

No entanto, em meio ao modismo que tem envolvido a crítica descolonial e a superficialidade com que, frequentemente, tem sido abordada é preciso, brevemente visitar esta teoria e seus principais conceitos.

Considerando que momentos políticos impactantes produzem oportunismos históricos, também se deve considerar que produzem movimentos teóricos. Desde meados do século XX, as guerras mundiais e os genocídios que delas foram gerados impulsionaram, das margens, a emergência de exterioridades sedentas de justiça à sua história de subjugação, de direitos à cidadania e dignidade. Como sinaliza Dussel (2019), tais exterioridades são chamas de carvão enterrado no mar de cinzas centenárias do colonialismo e anunciam a necessidade de operar a partir de lógicas anti-imperialistas para a construção de novos caminhos para estar, pensar, existir, olhar, escutar, e viver, neste mundo.

Reexistir depende de caminhos outros, epistemologias outras, universidades outras, conteúdos outros, práticas sociais outras, políticas outras como nos sugere o 
filósofo Abdélkebir Khatibi ${ }^{6}$, o ativista da descolonização Walter Mignolo (2003) e o filósofo intercultural Raúl Fornet-Betancourt (2017). Mas, operar em outra lógica significa ter ciência da Modernidade enquanto auto narrativa europeia elaborada a partir do século XVI com a anexação da Ameríndia. Não é possível compreender o porquê de discursos e práticas do conservadorismo e os fundamentalismos na atualidade e, pensar caminhos para a desarticulação dessas práticas perdendo de vista o encobrimento de Abya Yala e sua substituição pela América.

Nesta perspectiva, o Pensamento Descolonial, representado pelo coletivo Modernidade/Colonialidade ${ }^{7}$, apresenta a versão marginal sobre o início da história mundial com a implementação do colonialismo em Abya Yala. A colonização dessa terra impulsionou a Modernidade (sua versão europeia) e o estabelecimento de um padrão de poder mundial, o capitalismo. O principal postulado desse pensamento: Modernidade e Colonialidade são constitutivas.

A constituição da Modernidade e da Colonialidade desembocou no estabelecimento de uma ordem mundial, o Sistema Colonial Moderno,denunciada por uma geopolítica do poder: o centro do capital, da cultura e da política se localiza na Europa e seu descendente, os Estados Unidos. À margem desse sistema a América Latina, países asiáticos, África e parte da Europa. Uma estrutura hierárquica racial, cultural e epistémica, de gênero e religiosa constituem o Sistema Mundial Moderno: a matiz colonial de poder.

A Modernidade enquanto auto narrativa europeia traduz uma pretensa excepcionalidade dos europeus ${ }^{8}$ e seus descendentes, os estadunidenses. Evolução, desenvolvimento técnico cientifico, racionalidade, civilização e monoteísmo são os conteúdos dessa narrativa que se contrapõe ao outro visto como primitivo, sem capacidade cognitiva, irracional, bárbaro e politeísta. A destruição do outro, do não europeu, bem como da sua linguagem, padrão de expressão, práticas religiosas,

\footnotetext{
${ }^{6}$ Filósofo e crítico literário marroquino que se dedicou ao movimento da contracultura na região do Magrebe. Propagador do Pensamento-outro Khatibi, que parte do princípio da possibilidade do pensamento a partir da decolonização. Essa enquanto luta contra a invisibilidade, a não-existência.

7 O Grupo Modernidade/Colonialidade é formado por intelectuais marginais que militam em favor da descolonização. São representantes desse pensamento Aníbal Quijano, Enrique Dussel, Walter Mignolo, Nélson Maldonado-Torres, Maria Lugones dentre outros.

${ }^{8}$ Nos referimos ao que se costumou denominar de caminho excepcional da Europa que teria seu início na Renascença.
} 
saberes, conhecimentos e estética constituem a colonialidade.

O filósofo Nelson Maldonado Torres (2007) estabelece com clareza a diferença entre Modernidade e Colonialidade do poder:

O colonialismo denota uma relação política e econômica, na qual a soberania de uma nação está no poder de outra ou nação o que constitui a última em um império. Diferente desta ideia, a colonialidade se refere a um padrão de poder resultante do colonialismo moderno, não se limita a uma relação formal de poder entre a nação dominada e a dominadora se estende ao controle das formas de trabalho, do conhecimento, da autoridade e das relações intersubjetivas que se articulam mediante o mercado capitalista mundial e, mediante a ideia de raça. A colonialidade permanece pós colonialismo, está vida nos textos didáticos, nos critérios para o bom trabalho acadêmico, na cultura, no senso comum, na autoimagem dos povos, nos desejos e aspirações dos sujeitos, na religião, nas relações sociais, na relação entre homens e mulheres, na arte, na estética. Respiramos a colonialidade na modernidade cotidianamente. (TORRES, 2007, p. 131).

A Colonialiade do poder, como nos diz Aníbal Quijano (1992), traduz também a invasão do imaginário do outro, sua ocidentalização. É o discurso do colonizador se inserindo no mundo do colonizado e reproduzindo a ideia de que ele, colonizado, é inferior. É importante dizer que a ideia de inferioridade alcança amplitude na medida em que se refere às línguas, conhecimentos, religiões, arte, estética, raça e cor da pele de forma tal que os colonizados passam a aspirar o universo cultural europeu. Assim se justifica a força do eurocentrismo nas escolas, na gestão pública e, na produção cultural dos países colonizados.

O processo de subjugação colonial - colonialidade em movimento -, invisibiliza e subalterniza a ponto do colonizado negar, combater e esquecer os processos históricos pelos quais foi subjugado. Assim se explica o esquecimento da história do povo negro neste país. A árvore do esquecimento simboliza não apenas o olvido mas, sobretudo, a subalternização dos seus saberes, sistemas de crença, práticas epistémicas e corpos. Assim se explica a negação do ser negro, inclusive, pelo próprio negro. O racismo estrutural ou parasitismo racial deforma subjetividades negras ao desumanizar negras e negros que não se querem como tal e buscam o embranquecimento.

A colonialidade do poder, portanto, constrói a subjetividade do subalternizado 
e, a noção de raça é sua chave de leitura. Neste texto, a, noção de raça vinculada à cor negra.

Reiterando, Modernidade e Colonialidade são as duas faces da mesma moeda. Graças à colonialidade, a Europa pôde produzir as ciências humanas como modelo único, universal e objetivo na produção de conhecimentos, além de impor o degredo as epistemologias das periferias do ocidente.

No entanto, desde meados do século $\mathrm{XX}$, teorias críticas e movimentos sociais periféricas e marginais têm se levantado contra o Sistema Mundial-Colonial Moderno e seu padrão mundial de poder. Buscam abrir fissuras nesse sistema com vistas à libertações e transformação da modernidade. Anunciam a necessidade de operar a realidade a partir de lógicas não eurocêntricas.

Operar em outra lógica exige desprendimentos (Conceito descolonial) e abertura. É o que se percebe na obra libertária de Paulo Freire pensador marginal que como Simón Bolívar, José Martí, Manoel Bomfim e Leopoldo Sea ousou desprender-se da lógica eurocêntrica-ocidental em direção à de(s)colonialidade pois,

o pensar descolonial latino-americano, marginal, não é exclusivo da contemporaneidade. Tal como o expressa Mignolo (2007, p. 28, tradução nossa), "embora a reflexão sobre o giro epistêmico decolonial seja recente, a prática epistêmica decolonial surgiu "naturalmente" como consequência da formação e implantação da matriz colonial de poder[...] (BORGES; SENRA, 2021, p. 07).

Enquanto um pensador fronteiriço, no espaço da diferença colonial, entre a Modernidade e a Colonialidade Paulo Freire (1987) sugere pedagogias outras. Pedagogias construídas a partir de contextos locais a exemplo da Pedagogia Decolonial construída por Catherine Walsh que se inspira na epistême freriana.

\section{O IDEAL LIBERTÁRIO EM PAULO FREIRE E DE(S)COLONIALDIADE RACIAL}

$\mathrm{Na}$ fronteira de influencias como o personalismo de Emmanuel Mounier, o existencialismo, a fenomenologia e o marxismo, Paulo Freire sistematizou uma pedagogia que nos traz esperança. Associa humanismo e marxismo, temas cristãos e temas marxistas na construção de uma pedagogia da ação para libertação. Em seu pensamento está claro o desprendimento, a abertura e o estar na fronteira. Um aspecto 
de(s)colonial melhor vislumbrado no trágico dilema do oprimido-opressor que pressupõe tensões axiológicas conscientes e não conscientes no oprimido: ser ou não ser opressor!

Esse dilema ganha destaque em suas reflexões no texto Pedagogia do Oprimid, (1972), uma vez que sua preocupação central é com as condições existenciais das classes pobres, os oprimidos, que se encontram sob um sistema injusto que estimula nos opressores a violência e, desumaniza o oprimido e opressor. Frear as tensões interna e externa que envolvem opressor e oprimido é responsabilidade da educação e, como pensa Paulo Freire (1987) não há prática social mais política do que a educativa. Ainda que a educação possa ocultar a dominação e alienar, pode também denunciar a dominação e pensar novos caminhos, novas lógicas com vistas a de(s)alienações.

Seu projeto de educação inclui traçar caminhos metodológicos e analíticos para o reconhecimento da realidade de opressão. Sem tal reconhecimento não é possível conscientização, senso político, transformação da realidade e, libertação no sentido de(s)colonial. Neste projeto a análise das condições vividas pelos mais pobres, sua exclusão da cidadania são prioridades, inclusive, para a compreensão do que Manoel Bomfim denomina de parasitismo social e Aníbal Quijano de Colonialidade do Poder.

Tal análise político-social é essencial para sair do dilema que assola a todos nós enquanto oprimidos-anfitriões do opressor. Para Paulo Freire (1987), a luta para superação dessa tensão faz da pedagogia um importante elemento político constituído de uma dinâmica critica onde, constante, a pedagogia se faz e se refaz.

A pedagogia do oprimido destaca a responsabilidade de pensar criticamente e aprender a ser um na relação com seu próprio ser. O que nos leva a pensar à luz de Freire que na luta pela libertação/de(s)colonialidade o oprimido pode ser opressor pois como lutar efetivamente contra a opressão do Sistema Mundial Moderno se a consciência não é crítica? Se aquele que se coloca como militante insistir em práticas coloniais e opressoras como o machismo, o racismo, a intolerância religiosa, a homofobia?

A luta contra a opressão é, sobretudo, a luta contra o ser opressor que nos constitui pois a estrutura do nosso pensar sobre o mundo e as relações que estabelecemos se encontram condicionadas pela contradição vivida na situação concreta, existencial, em que se "formou". Se somos "formados" como oprimidos somos 
também como opressores. O que concede à luta contra a estrutura hierárquica do Sistema Mundial-Colonial Moderno e o seu padrão de poder, o capital uma exigência fundamental: a libertação de si mesmo no sentido, a autodescolonização.

Direcionando o dilema opressor-oprimido à causa negra, não causa surpresa a seguinte constatação: quase duas décadas depois a Lei 10.639/2003 que obrigava a inserção de temáticas afro-brasileiras na educação e, depois transformada na Lei 11.645/2008 que já prevê o ensino da cultura indígena, não conseguiu se efetivar plenamente na educação básica e na universidade. A resistência de professores e acadêmicos na compreender ad própria cultura revela o dilema opressor-oprimido na educação básica e no ensino superior.

Como combater as hierarquias raciais sejam na dimensão corporal, religiosa e epistémica se a educação resiste à descolonização do parasitismo racial? Como pode ser possível uma pedagogia construída pelo oprimido com vistas a recuperar sua humanidade sem a de(s)colonialidade? Sem a libertação da colonialidade do poder?

A extinção ou superação do parasitismo racial e da colonialidade do poder, isto é, a de(s)colonialidade somente é possível com a aceitação do dilema opressor-oprimido colocada por Paulo Freire (1987). A consciência crítica sobre tal dilema deve estar expressa nos conteúdos da educação básica e dos cursos universitários. Isso de forma clara e contundente e, não revestida de palavras como transversalidade, multidisciplinaridade e diversidade. A luta contra a opressão exige clareza sobre o que se está combatendo e porque se está combatendo. O contrário mantém a educação, nas regiões colonizadas, instrumento de manutenção da opressão e distante da luta em favor da libertação e de(s)colonialidade.

Para Paulo Freire (1987), a vida implica o exercício de uma ética humana no mundo e com o outro. O que faz da ética inseparável da prática educativa. Ainda que Freire ao longo de suas produções tenha se prendido à discriminação de classe, enquanto formidável pensador que se liberta do ser opressor que o impedia de vislumbrar questões relacionadas à gênero e raça, escreve pouco tempo antes de sua morte, em 1992 A Pedagogia da Esperança. Nesta obra, em uma escrita quase autobiográfica, pensa o poder e a opressão não mais apenas reduzidos aos fatores econômicos mas também a partir da racialização e da colonização. 
Oportunidade para a ativista da descolonização e estudiosa de Paulo Freire, Catherine Walsh (2013) reiterar a necessidade de uma educação via pedagogias de ação, via a aliança entre o pedagógico e o decolonial ${ }^{9}$ com vistas à humanização. Nos diz essa militante da de(s)colonialidade:

La deshumanización -entendida como "el resultado de un orden injusto que genera la violencia de los opresores, lo que, en cambio, deshumaniza los oprimidos" - es, para Freire, una distorsión de la vocación de hacerse más plenamente humano. Enfrentar este problema haciendo que el ser humano llegue a tener consciencia de esta condición y que reconozca la necesidad de luchar por la restauración de su humanidad, son pasos necesarios - pero no únicos- en su pedagogía y praxis humanista y liberatoria hacia la emancipación (Freire, 1974b: 74).19 La creación de estructuras socioeducativas que equipan los "oprimidos" con las herramientas necesarias para des-velar las raíces de su opresión y deshumanización, identificar sus estructuras, y actuar sobre ellas, también son componentes céntricos.(WALSH, 2013, p. 48)

A educação emancipadora, portanto, se coloca como urgente se considerarmos a realidade atual brasileira marcada pelo crescimento de uma mentalidade religiosa, conservadora, fundamentalista, machista e homofóbica. Uma mentalidade totalmente em sintonia com o Sistema Mundial-Colonial Moderno e seu padrão de poder racista, o capitalismo.

Uma mentalidade que fortalece a matriz colonial de poder e desumaniza oprimidos e opressores.

A desumanização, que não se verifica, apenas, nos que tem sua humanidade roubada, mas também, ainda que de forma diferente, nos que a roubam, é distorção da vocação do ser mais. É distorção possível na história, mas não vocação histórica. Na verdade, se admitíssemos que é vocação histórica dos homens, nada mais teríamos que fazer, a não ser adotar uma atitude cínica ou de total desespero. A luta pela humanização, pelo trabalho livre, pela desalienação, pela afirmação dos homens como pessoas, como 'seres para si', não teria significação. Esta somente é possível porque a desumanização, mesmo que um fato concreto na história, não é, porém, destino dado, mas

\footnotetext{
${ }^{9}$ Usamos o termo em o $\mathrm{S}$ em respeito e fidelidade ao pensamento da autora que optou em pensar a descolonização como decolonialidade. Sobre as implicações sobre o uso com $\mathbf{S}$ ou sem o $\mathbf{S}$ vide BORGES, Ângela C.; SENRA, Flávio (2020). "Epistemologias marginais: Ciências da Religião em perspectiva descolonizadora e intercultural". Reflexão, 45, p.1-16,2020.
} 
resultado de uma 'ordem' injusta que gera a violência dos opressores e esta, o ser menos. (FREIRE, 1987, p. 16)

Uma virada epistêmica descolonizadora antiracial é necessário na educação para reintegrar aos seres humanos sua humanidade. Paulo Freire nos alerta sobre essa difícil tarefa pois "a libertação, por isto, é um parto. E um parto doloroso. O homem que nasce deste parto é um homem novo" (FREIRE, 1987, p. 19).

O caminho decolonial apontado por Catherine Walsh (2013) a partir de Paulo Freire, caminho esse já irradiado por Manoel Bomfim é urgente. A face opressora da universidade e das escolas brasileiras deve ser desmantelada por pedagogias outras, de(s)coloniais e de(s)parasitadas o que não será possível sem a categoria de raça em suas reflexões.

A compreensão do que seja racismo estrutural passa pela compreensão da invenção da América e da história colonial que esse fato desencadeou ao longo dos séculos. A noção de racismo estrutural concede visibilidade à histórica de luta do povo negro durante o colonialismo quando práticas, metodologias, pedagogias de luta, insurgência e resistência de africanas, africanos e descendentes foram empregados para transgredir e subverter a dominação colonial. Uma história de de(s)colonialidades.

Fissuras foram abertas e um pensar, agir, sentir e reexistir de(s)colonialmente ocorreu. As casas de Zungu, os batuques, as terreiradas, os cantos, a oralidade, a poesia, o fazer ritualístico afro-brasileiro comprovam a existência de pedagogias da ação, de pedagogias outras.

Mas, porque ainda, saberes e conhecimentos negros, historicamente, foram tomados como folclore nas escolas e até nas academias brasileiras? porque práticas epistémicas negras somente agora nos últimos anos passam a ser consideradas por técnicos do conhecimento que antes as ignoravam? Mas que agora tateiam sobre temáticas negras e afro-brasileiras nas redes sociais? Será o oportunismo histórico? Uma nova forma de parasitismo racial? Outra roupagem da colonialidade do poder?

Considerando que momentos históricos impactantes provocam espantos, há que se considerar que técnicos de conhecimentos, intelectuais e educadores, bem como qualquer brasileira e brasileiro, em algum momento durante a pandemia, pensou na necessidade de operar o mundo e as relações a partir de outras lógicas. 
Uma educação de(s) colonial em direção ao fim da colonialidade do poder e do parasitismo racial tão bem expressos no dilema oprimido-opressor, em momentos como esse pode promover o diálogo com "outras" culturas. Nos referimos às culturas africana e indígena no Brasil - afro-brasileira, afro-indígena - um diálogo com nossas culturas imêmores na árvore do esquecimento mantida pelo nosso eu opressor.

Neste caso, o diálogo é intercultural mas interno, uma vez que,

O importante do ponto de vista de uma educação libertadora, e não bancária, que, em qualquer dos casos, os homens se sintam sujeitos do seu pensar, discutindo o seu pensar, sua própria visão do mundo, manifestada implícita ou explicitamente, nas suas sugestões e nas de seus companheiros (FREIRE:1987, p.75).

A educação libertadora tão bem sistematizado por Paulo Freire e sonhada por Manoel Bomfim também é educação para a interculturalidade. Como defende Catherine Walsh (2012, p.66)) interculturalidade se entende :

como una estrategia, acción y proceso permanentes de relación y negociación entre, en condiciones de respeto, legitimidad, simetría, equidad e igualdad. Pero aún más importante es suentendimiento, construcción y posicionamiento como proyecto político, social, ético y epistémico -de saberes y conocimientos -, que afirma la necesidad de cambiar no sólo las relaciones, sino también las estructuras, condiciones y dispositivos de poder que mantienen la desigualdad, inferiorización, racialización y discriminación.

A interculturalidade, portanto, inibe não apenas as sete ou nove voltas na árvore do esquecimento imposta pela ocidentalização colonial mas também a destitui de vitalidade.

\section{REFERÊNCIAS}

ALMEIDA, S. O que é racismo estrutural? Belo Horizonte, Minas Gerais: Letramento, 2018.

BOMFIM, Manoel. América latina; males de origem. Rio de Janeiro, RJ: Biblioteca básica brasileira, 2008.

BORGES, Ângela C.; SENRA, Flávio (2020). “Epistemologias marginais: Ciências da Religião em perspectiva descolonizadora e intercultural”. Reflexão, 45, p.1-16,2020. 
DUSSEL, Enrique. "Transmodernidade e Interculturalidade: interpretação através da filosofia da libertação." Sociedade e Estado, v.31, n.1, p.51-73, 2016. Disponível em:http://www.scielo.br/pdf/se/v31n1/0102-6992-se-31-01-00051.pdf. Acesso em 16 jan,2019.

FORNET-BETANCOURT, Raúl. "Universidad e interculturalidad. Hacia una conjuración para la transformación intercultural de la universidad." In: FORNETBETANCOURT, Raúl. Elementos para una crítica intercultural de la ciencia hegemónica. Aachen: Concórdia, n.71, p.45-57, 2017.

FREIRE (1987), Paulo. Pedagogía do Oprimido. Rio de Janeiro: Paz e Terra, 1987.

QUIJANO, Aníbal. "Colonialidad y modernidad-racionalidad." In: BONÍLIA, Heraclio (Compilador). Los conquistados. 1492 y la población indígena de las Américas. Bogotá: Tercer Mundo Editores, 1992.

MALDONALDO-TORRES, Nelson. "Sobre la colonialidad del ser: contribuciones al desarrollo de un concepto." In: CASTRO-GÓMES, Santiago; GROSFOGUEL, Ramón. El giro decolonial. Reflexiones para una diversidad epistémica más allá del capitalismo global. Bogotá:Siglo del Hombre Editores,2007.

MIGNOLO, Walter. Histórias locais/projetos globais. Colonialidade, saberes subalternos e pensamento liminar. Trad. Solange Ribeiro de Oliveira. Belo Horizonte: Editora UFMG, 2003

WALSH, Catherine. Interculturalidad y (de)colonialidad: Perspectivas críticas y políticas. Visão Global, Joaçaba, v. 15, n. 1-2, p. 61-74, jan./dez.,2012

WALSH, Catherine. Pedagogías decoloniales: prácticas insurgentes de resistir, (re)existir y (re)vivir. Tomo I. Quito, Ecuador: Ediciones Abya-Yala, 2013. 553 p.

WALSH, Catherine. "Interculturalidad y colonialidad del poder. Un pensamiento, un posicionamiento otro desde la diferencia colonial." In: LINERA; MIGNOLO; WALSH. Interculturalidad, descolonización del Estado y del conocimiento. Buenos Aires: Edições Del Signo, 2014. 